\title{
Exploration on the Planning of Characteristic Towns Based on the Theory of Edge City
}

\author{
Tao Wang \\ Shenyang Aerospace University \\ Shenyang, China
}

\begin{abstract}
In the development process of characteristic towns, due to the imbalance of policy and investment, the disharmony between industry and population, the ambiguity of construction objectives and many other reasons, the economic development is not smooth and the attraction of talent is not enough. This paper combines the theory of edge cities, compares the similarities and differences between characteristic towns and edge cities, and explores the relationship between the edge cities and characteristic towns at the planning perspective. Based on the advantages of environment and resources of characteristic towns, this paper explores the planning of characteristic towns from the aspects of industry cultivation, regional traffic, population flow and supporting facilities, in order to avoid the problems faced by characteristic towns in the process of development at this stage.
\end{abstract}

Keywords-edge cities; Characteristic towns; planning

\section{INTRODUCTION}

Characteristic towns are the product of China's new urbanization process. Unlike the traditional designated towns, characteristic towns combine the four elements of industry, city, stream of people and culture in a form of industrial development platform. Practice has proven that relying on the competitive industry or regional resources, characteristic towns have greatly enhanced the attraction of regional talents and promoted the upgrading of regional industries through the introduction of supporting infrastructure. Since the concept of characteristic towns has been put forward, these towns have ushered in the explosive growth. However, there are many faulty aspects in the development process of characteristic towns. The indistinctive industrial characteristics and over-reliance on investment have led to the formation of industrialization of town real estate with "little investment, short duration but quick result". The ambiguous concept and lack of emphasis on planning and construction have caused "large and complete" economic development regionalization. Because the purpose of development is not clear, the characteristic towns have become vanity projects and the local economy has been put more emphasis on the number rather than actual project. It can be seen that it is particularly important to make reasonable planning for industrial selection, regional connectivity, pedestrian attraction and supporting facilities before building characteristic towns.
In the process of development, the big cities of America have undergone a transition from a single center to a multicenter, and edge cities have been formed because the industries and people moved from central cities to suburbs. Edge cities have effectively alleviated the population pressure of the central cities, promoted the diversified distribution of urban space, and played a significant role in regional development. And the theory of edge city systematically studies the generation and regional benefits of edge cities.

There are many similarities between characteristic towns and edge cities in the planning. Therefore, from the perspective of the theory of edge city, this paper takes the essence, combines China's national conditions and the current construction of characteristic towns, and puts forward the planning methods for characteristic towns from the aspects of industry, transportation, humanities, supporting facilities to provide reference solutions to the problems in the construction and development of characteristic towns.

\section{CHARACTERISTIC TOWNS AND EDGE CitIES}

\section{A. Characteristic Towns}

Since the concept of "characteristic town" was proposed in 2014, the characteristic town has been strongly supported by the policy, and the "town fever" has swept across the country. Statistics show that at present the number of characteristic towns is 403 in national level, more than 2,000 in provincial level, more than 6,000 in municipal level, and more than 7,000 in county level. The concept of characteristic town is proposed in the context of new urbanization. Compared with the traditional designated towns and industrial parks, the characteristic towns in essence are closer to an industrial development platform. Depending on natural endowment of environment and resource in this region, it selects and cultivates characteristic industries that are in line with its own development, creates job opportunities with characteristic industries to attract high-level talents, improves regional advantages to attract investment, and optimizes urban layout, so as to achieve the goal of building distinctive and charming characteristic towns with a fusion of city and industry in line with local conditions.

Functionally, with characteristic industries as the core, characteristic towns promote characteristic industries and 
expand industrial chain by means of efficient information technology and convenient transportation system, and realize the penetration, crossing and reorganization among different industries with characteristic industries as the center, thus enriching the regional industrial gradient, promoting the upgrading of regional industrial structure, and improving the employment rate and core competitiveness of regional industries. Moreover, characteristic towns have a certain population attraction, which can effectively attract rural population while alleviating the population pressure of big cities. It promotes the bidirectional flow of the population, and then upgrades the self-restoration function of cities.

\section{B. Edge Cities}

Edge cities are the product in the course of the big cities of America changing from a single center to a multi-center, and present a decentralized, multi-node networked feature in space. Currently, there is no clear definition about edge cities. In 1991, Joel Garreau, in his book Edge City: Life on the New Frontier, described edge cities as a comprehensive central area integrating functions of commerce, residence and employment, which is developed in the suburbs around the original central cities, and put forward a criteria to define edge cities from the five aspects of area of rentable office buildings, area of rentable shops, number of jobs and bedrooms, mental regional specificity, and landscape distinctiveness within 30 years. Based on the number of private cars and convenient expressway system and in virtue of the innovation of network and communications technology, edge cities have realized the informationization, decentralization and flexibility of industrial development; unbounded spatial distribution, fragmentation of control, and administrative non-autonomy; ecological, humanized and low-density living conditions. Edge cities strengthen the connection and communication with peripheral cities and weaken the effect of central cities, so as to solve the problems of single central cities including single spread, space disorder and heavy traffic pressure in the development process. Therefore, based on the existing literature and the opinions of domestic and foreign experts, the author believes that edge cities are an effective and compromised means for large cities in developed countries of Europe and the United States, which can be simply described as the area with the functions of residential, employment, and commerce established in the suburbs around the central city. We transfer the population to the suburban areas by means of convenient transportation system and communication to alleviate the pressure of the central city, relocate enterprises to provide job opportunities for the suburban population, create humanized supporting facilities matching leisure infrastructure, and ensure a sustained and strong regional appeal, so that edge cities can become a comprehensive and dynamic new urban area.

\section{Theory of Edge City}

The theory of edge city is a method to analyze and study edge cities. It describes and reflects the generation process, growth form, functional characteristics, development direction and impact of edge cities in a comprehensive and systematical way. The theory of edge city places emphasis on the three aspects: generation and development of edge cities, regional influence of edge cities, and the impact of information society on edge cities' development. The theory of edge city describes the characteristics of edge cities, gives the standard to define them, and classifies them by types. It also studies and interprets the functions and impacts of edge cities from the perspective of region, and forecasts the impact of information and network society on the development of edge cities.

\section{Similarities and Differences Between Edge Cities and Characteristic Towns}

1) Similar supporting conditions and different locational conditions: Convenient means of information communication is the premise of smooth communication between edge cities and characteristicstowns, and efficient transportation system provides guarantees for the stream of people and logistics in edge cities and characteristics towns. There are similarities between the supporting conditions of edge cities and characteristic towns. Edge cities locate in the suburb of the city, and far away from the central cities. Therefore, edge cities often put more emphasis the efficiency of transportation system, and their main vehicles are private cars. Characteristic towns are more flexible in location distribution, which can not only be adjacent to the city center but also developed from independent villages and towns located in the outer suburbs of the city. So, when planning characteristic towns, there are more possibilities in transportation construction, and the choice of transportation means is also more diversified.

2) Similar construction style and features and different development scale: In the construction of edge cities and characteristic towns, landscape advantages of the region itself and local cultural precipitation are primary considerations. We should combine with local conditions and customs and regional culture in terms of construction style and features of edge cities and characteristic towns, fully satisfy the functions of characteristic towns and edge cities in the form and function of buildings, and be committed to creating efficient, integrated and multifunctional building spaces and community systems. However, in terms of development scale, edge cities should include over $464,500 \mathrm{M} 2$ of rentable office area and over $56,000 \mathrm{M} 2$ of rentable shop area based on the defining conditions for edge cities by Joel Garreau. Edge cities emphasize low building floors, low building density and high greening rate. The development of characteristic towns put more emphasis on scale constraints, and the planned area is generally controlled at about 3 square kilometers. It stresses the planning idea of "small space and large gathering, small platform and big industry, small carrier and big innovation", and strives for the core and integration of characteristic industries.

3) Similar organizational form and different development motivation: Edge cities provide more jobs by relocating enterprises from the central cities, so investors are 
enterprises and the operation mode is market-oriented in edge cities. The formation of edge cities is more spontaneous with less government intervention., but the motive force of development of edge cities mainly comes from the market orientation. Therefore, edge cities are the product of urban spatial reorganization and functional reconstruction. The characteristic town takes characteristic industries as the core, and its investors are mainly enterprises. However, characteristic towns need the guidance of the government in the mode of operation. A new government and enterprise cooperation model is guided by policy to lead the inflow and allocation of capital and talents and supplemented by the operation of professional teams. The policy inclination and the government's support are the motive force of development for characteristic towns.

4) Similar dominant functions and different industry linkage: The industries in edge cities mainly include production and service industry and life service industry. Their development model mainly takes professional service industries to drive the development of regional economy, so as to disperse the stream of population, promote industrial upgrading, and enhance regional employment rate in function. Most of industries in edge cities come from the industrial migration from the central cities, which drives the population from the central cities to the periphery. Therefore, the industrial linkages of edge cities tend to be a crossregional linkage model of the same industry. The dominant functions of characteristic towns are similar to those of marginal cities, which drives the movement of urban population with the development of industries, reduces the population pressure of central cities, provides jobs for rural population, and boosts the development of regional economy with the upgrading of industries. But the characteristic towns take characteristic industries as a core, rely regional economical plates and strengthen fusion and recombination of different industries. Therefore, the industrial linkage of characteristic towns is concentrated on the organic industrial network formed by characteristic industries.

\section{THE INSPIRATION OF THE THEORY OF EDGE CITIES TO THE PLANNING OF CHARACTERISTIC TOWNS}

\section{A. To Promote the Integration of Industries and Cities Oriented by Characteristic Industries}

A systematic study from the perspective of the emergence, development and definition of edge cities based on the theory of edge city shows that we should take government orientation as the blueprint, advantages of environment and resources as the cornerstone, high-level talents as the construction, enterprise investment as the framework, and market as motive force in the planning of characteristic towns. Meanwhile, we should select and cultivate characteristic industries according to local conditions, give full play to industrial characteristics and urban advantages, and explore the links among related industries in the region, so as to make the industrial functional layout match its spatial layout, enrich industrial gradient and promote the integration of industry and city. We should establish a scientific and effective diversified development evaluation system for characteristics towns, to make the planning objectives fully conform to the assessment objectives and avoid the industrialization of real estate in characteristic towns due to over-reliance on investment, divorcing from the actual situation and weakening the industrial development in the planning process.

\section{B. To Attach Importance to Regional Linkage Supported by Green Transportation}

The theory of edge cities analyzes the influence and benefits of edge cities within the region. In the planning of characteristic towns, we should not only pay attention to industrial linkage, but also set our sights on region, integrate green transportation theory in it, and build an intensive and complex transportation system on the premise of low energy consumption and low pollution. We will reasonably combine rail transit and bus lines to optimize traffic organization and improve transport efficiency between regions. Moreover, we should take green transportation as the network, put emphasis on regional connectivity and interaction, give full play of central role and linkage function of characteristic towns in the space, and motivate regional industry's network gathering in all areas by drawing upon the experience gained on key points, so as to make a close connection of characteristic towns and big cities.

\section{To Achieve Industrial Innovation with Hi-end Talents as the Driving Force}

In the planning of characteristic towns, we should ensure the attraction of high-end talents, give full play to the selfrestoration function of characteristic industries, attract talents by industrial advantages, promote innovation with talents, and reform industries with innovations. We should provide a reasonable community planning for characteristic towns, strengthen the neighborhood relationship between people, and pay attention to the job-housing balance. With the help of scientific and technological means to weaken the influence of distance, the wisdom of life in towns and intelligence of production in towns can be realized.

\section{To Build a Livable Environment Based on Ecological Culture}

We will plan the architectural style supporting facilities of towns with a purpose, and care for people. Based on the regional eco-culture selected by characteristic towns, combined with the era characteristics of openness and network, we will build a distinctive space for the coordinated development of "production, ecology and life". In view of types of people attracted by industries in characteristic towns, and together with people structure and regional cultural foundation, we will match integrated business, food, leisure space, and build a public service system, so as to create a humane ecological environment that is pleasant and suitable for production. 


\section{CONCLUSION}

We will adopt another's good quality or suggestion to remedy our own defects. The theory of edge city has four main inspirations for the research and description of edge cities in the planning of characteristic towns: the first is to proceed from reality and make a planning around characteristic industries; the second is to attach importance to regional connectivity and introduce green traffic; the third is to focus on the promotion of talents to industrial innovation and maintain the town's attraction to talents; the fourth is to lay emphasis on ecological environment construction and improve supporting facilities. Based on the interpretation of edge cities and their theory, this paper combines with the national conditions and features of characteristic towns, and proposes a new path for the planning of characteristic towns in China, in order to provide reference for the construction and development of characteristic towns.

\section{REFERENCES}

[1] Garreau J. Edge City: Life on the New Urban Frontier[M]. New York: Doubleday. 1991

[2] He Wenjing. Study on the Formation Mechanism and Development Model of China's Edge Cities[D].Changchun: Northeast Normal University, 2012. (in Chinese)

[3] Ke Min. From the Perspective of Edge Cities, the Construction Path of Characteristics Towns - Take an Example of Jiashan Shanghai Talent Entrepreneurship Town [J]. Development of Small Cities \& Towns. 2016(3):49-53. (in Chinese)

[4] Li Guanghui. Development Path of China's Urban Integration[D]. Anhui University, 2014. (in Chinese)

[5] Liu Yuting, Cheng Hui. The Research Progress on Edge City in China and Foreign Countries[J]. Urban Planning International, 2013(3):52-58, 77. (in Chinese)

[6] Sun Yifei, Ma Runchao. Edge City: A New Trend in Urban Development in the United States[J]. Urban Planning Overseas, 1997(4): 28-35.

[7] Wu Xiao, Ma Hongjie. Preliminary Investigation on Edge City Formation and Morphology[J]. Huazhong Architecture, 2000(4): 8586.

[8] Yang Yongchun. Conceptual Planning of Lanzhou City[M]. Lanzhou: Gansu People's Publishing House, 2004. (in Chinese)

[9] Zhu Mengjue, Zhou Chunshan. From Contiguous to Leaping Expansion: Spatial Expansion Transition of China's New Districts[J]. Planners, 2013, 29(7): 79-84. (in Chinese) 